\title{
Utility and validity of DISC1 mouse models in biological psychiatry
}

\author{
Toshifumi Tomoda ${ }^{1, *}$, Akiko Sumitomo $^{1}$, Hanna Jaaro-Peled ${ }^{2}$, and Akira Sawa, ${ }^{2, *}$
}

1. Medical Innovation Center, Kyoto University Graduate School of Medicine, Kyoto 606-8507, Japan 2. Department of Psychiatry and Behavioral Sciences, Johns Hopkins University School of Medicine, Baltimore, MD 21287, USA

* Correspondence: asawa1@jhmi.edu, tomoda@tk.med.kyoto-u.ac.jp 


\begin{abstract}
We have seen an era of explosive progress in translating neurobiology into etiological understanding of mental disorders for the past 10-15 years. The discovery of Disrupted-in-schizophrenia 1 (DISC1) gene was one of major driving forces that have contributed to the progress. The finding that DISC1 plays crucial roles in neurodevelopment and synapse regulation clearly underscored the utility and validity of DISC1-related biology in advancing our understanding of pathophysiological processes underlying psychiatric conditions. Despite recent genetic studies that failed to identify DISC1 as a risk gene for sporadic cases of schizophrenia, DISC1 mutant mice, coupled with various environmental stressors, have proven successful in satisfying face validity as models of a wide range of human psychiatric conditions. Investigating mental disorders using these models is expected to further contribute to the circuit-level understanding of the pathological mechanisms, as well as to the development of novel therapeutic strategies in the future.
\end{abstract}




\section{Introduction}

The Disrupted-in-schizophrenia 1 (DISC1) was initially identified as a gene disrupted by a translocation mutation co-segregating with major mental illnesses, such as schizophrenia and depression, in a Scottish pedigree (Millar et al., 2000). When this mutation was reported in 2000, the current levels of genomewide psychiatric genetics were not available. Thus, DISC1 was expected to be a major molecular lead to elucidate biological mechanisms underlying major mental illnesses. Has DISC1 met this expectation?

Recent genetic studies with large cohorts for schizophrenia and bipolar disorder have failed to provide convincing evidence for the role of DISC1 as a "genetic" contributor to sporadic cases of schizophrenia (Purcell et al., 2009; Fromer et al., 2014; Purcell et al., 2014; Kranz et al., 2015). Meta analyses also have not supported the idea that common variants of the DISC1 gene are associated with schizophrenia (Mathieson et al., 2012). Furthermore, genome-wide association studies have failed to identify DISC1 as a promising gene associated with schizophrenia in the current diagnostic frameworks (Ripke et al., 2013; Network and Pathway Analysis Subgroup of Psychiatric Genomics Consortium, 2015).

In contrast, in the first ten years since the discovery of the gene, studies using cells and model organisms that explore biological function of DISC1 in vitro and in vivo have been fruitful. Roles for DISC1 in neurodevelopment and synaptic regulation have been extensively characterized (Kamiya et al., 2005; Mao et al., 2009; Hayashi-Takagi et al., 2010; Singh et al., 2010; Ishizuka et al., 2011; Singh et al., 2011). These findings have become directly relevant to our understanding of disease processes (Fig. 1); compelling evidence is now available that biological pathways involving DISC1 and its protein network can play pivotal roles in the pathologies relevant to severe mental conditions, in particular those that may be shared among schizophrenia, autism, and mood disorder (Cross-Disorder Group of the Psychiatric Genomics Consortium, 2013; Network and Pathway Analysis Subgroup of Psychiatric Genomics Consortium, 2015). This is analogous to the role for Tau in the pathology of Alzheimer's disease (AD). The contribution of the Tau gene specifically to sporadic cases of AD may not be outstanding, in contrast to the ApoE gene (Piaceri et al., 2013). Nonetheless, the biological pathway involving the Tau protein plays a central role in AD pathology (Krüger and Mandelkow, 2015). Likewise, the potential value of the DISC1 protein as a "biological" lead in understanding molecular mechanisms for major mental illnesses is now appreciated.

In this review article, we will summarize recent updates on DISC1 genetically-engineered mice. Although many investigators, including our group, provided review articles on DISC1 mouse models in the past (Brandon and Sawa, 2011; Wong and Josselyn, 2015), the present article will highlight recent findings that were not well covered in the previous reviews. Furthermore, an addition of novel DISC1 models for the past 3-4 years has enlarged our perspectives of how we can use these models to address 
biological questions in major mental illnesses in a valid manner.

\section{DISC1 as a scaffold protein in neurodevelopment and synaptic regulation}

Molecular and cell biological studies revealed multifaceted roles of DISC1 in neurodevelopment and synaptic functions. DISC1 is an intracellular scaffold protein and interacts with many other proteins that are also known to play important roles for neurodevelopment and synaptic regulation. These interacting proteins include nuclear distribution protein NudE-like 1 (NDEL1), platelet-activating factor acetylhydrolase 1B subunit alpha (PAFAH1B1, a.k.a. LIS1), Bardet-Biedl syndrome 4 (BBS4), Girdin/KIAA1212, phosphodiesterase 4 (PDE4), Kalirin7, TRAF2- and NCK-interacting kinase

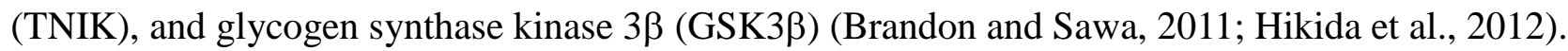
Recent studies have identified even more interactors of DISC1, such as dopamine D2 receptors (D2R) (Su et al., 2014) and mRNA for inositol-1,4,5-trisphosphate receptor type 1 (ITPR1) (Tsuboi et al., 2015). This led to the hypothesis that some, if not all, of these functions elicited by DISC1 together with its interactors likely underlie pathophysiology of major mental conditions. To test this hypothesis, a series of mouse models of Discl dysfunction have been generated through genetic manipulation. Perturbation of DISC1 may elicit an alteration in brain connectivity and function during developmental trajectory, which may underlie behavioral and cognitive phenotypes relevant to the diseases. Once such a link of the clinical manifestations to underlying biological mechanisms is elucidated through DISC1 mice, the models may also be useful for developing novel therapies based on mechanistic understanding (Brandon and Sawa, 2011).

In the following section, we will overview existing genetic mouse models for DISC1 dysfunction and discuss how each model has contributed to neurobiology and translational psychiatry.

\section{Haploinsufficiency models}

The chromosomal translocation found in the Scottish family disrupts DISC1 gene at intron 8 on one chromosome, while keeping this gene on the other chromosome intact. The disruption of the gene may lead to loss-of-function, possibly due to nonsense-mediated mRNA decay. Thus, the overall outcome elicited by this genetic mutation may be haploinsufficiency. Three models of loss-of-function of mouse Discl gene have been generated so far: (i) a model truncating exon 8 of Discl with an exogenously introduced stop codon on a genetic background that carries $\Delta 25 \mathrm{bp}$ deletion in exon 6 (called $\Delta 25 \mathrm{bp}$ hereafter) (Koike et al., 2006); (ii) a model deleting exons $2 / 3$ on a genetic background that has otherwise intact Disc1 gene (called $\Delta$ ex2/3) (Kuroda et al., 2011); and (iii) a model deleting a large locus spanning exon 1 through exon 3 on the exon $6 \Delta 25$ bp-carrying background (called Discl locusimpairment [Discl-LI]) (Shahani et al., 2015). 
Although $\Delta 25 \mathrm{bp}$ mice show deficits in working memory and $\Delta \mathrm{ex} 2 / 3$ mice show higher impulsivity phenotype, these models have displayed no additional behavioral endophenotypes that typically occur in major mental illnesses. However, recent detailed studies revealed cellular level abnormalities in these mice. $\Delta 25 \mathrm{bp}$ mice show erroneous axonal targeting, reduced dendritic growth of hippocampal neurons, and additional deficits in proliferation and dendritic complexity in developing dentate granule cells, accompanied by changes in short-term plasticity at the mossy fiber/CA3 circuit (Kvajo et al., 2011; Lepagnol-Bestel et al., 2013; Juan et al., 2014). $\Delta$ ex2/3 mice show a threshold shift in the induction of long-term potentiation (LTP) in dentate gyrus (Kuroda et al., 2011), and an exaggerated endoplasmic reticulum calcium response (Park et al., 2015), which could in part be due to defective dendritic transport of mRNA for ITPR 1, a known regulator for synaptic plasticity (Tsuboi et al., 2015). Additionally, Disc1-LI mice show aberrant trafficking of amyloid precursor protein (APP) in cortical neurons, which leads to aberrant C-terminal processing of APP and A-beta peptide generation (Shahani et al., 2015). These findings are in good agreement with the role of Disc1 in neuronal development and function revealed by previous cell biological studies (Brandon and Sawa, 2011; Narayan et al., 2013).

At present, it remains an open question as to how these haploinsufficiency models could directly contribute to biological understanding of the pathologies in major mental illnesses. As will be discussed

later, one caveat of these models might be that the molecular signatures and transcriptional landscape are not clear after these genetic mutations, partly due to the complex nature of Discl isoform expression, and potential effects of developmental compensation of the phenotypes caused by these mutations (Brandon and Sawa, 2011; Muraki and Tanigaki, 2015). Further studies are warranted on the circuitlevel disturbance and its causal link to subtle behavioral outcomes in these mice.

\section{Point mutation models}

$N$-nitroso- $N$-ethylurea (ENU)-mutagenesis approach in C57BL/6J mice led to the identification of two missense mutations of Disc1, Q31L and L100P, that led to depressive-like phenotypes and schizophrenic-like phenotypes, respectively (Clapcote et al., 2007). Additional studies on Q31L mice revealed imbalance in monoamine function, which may underlie reduced sociability and social novelty seeking activities seen in this model (Lipina et al., 2013). Cell biological studies on L100P mice revealed enhanced dopamine function (Lipina et al., 2010; Su et al., 2014), deregulated neurexin function (Brown et al., 2011), altered GSK3 $\alpha$ activities in synapses (Lee et al., 2011), as well as deficits in interneuron development (Lee et al., 2013). However, mice with the same mutations on a different genetic background showed phenotypes indistinguishable from the controls (Shoji et al., 2012). The data demonstrate a significant effect of genetic backgrounds on the manifestation of psychiatric phenotypes. Alternatively, subtle differences in animal handling, diet, and laboratory conditions may influence the 
behavioral outcomes, suggesting that environmental factors should be taken into account when interpreting the behavioral phenotypes, as will be discussed later. In addition, biochemical underpinnings of how the two mutations lead to contrasting behavioral outcomes that also display differential therapeutic responses remain to be explained.

\section{Transgenic models}

An alternative approach to model human DISC1 breakpoint mutation has been to express putative dominant-negative (DN) isoforms of DISC1 in mouse brains (Hikida et al., 2007; Li et al., 2007; Pletnikov et al., 2008; Shen et al., 2008). A great body of these studies agree that perturbation of Disc1 function by these transgenic approaches led to a myriad of anatomical, cell biological, and circuit-wide deficits, as well as behavioral consequences that are considered relevant to human psychiatric conditions. For example, enlarged lateral ventricles, reduction in parvalbumin-positive interneuron pools in prefrontal cortex and in hippocampus, hyperlocomotion, lowered prepulse inhibition (PPI), and social withdrawal-related behavioral phenotypes are largely common among these models (Brandon and Sawa, 2011).

Using these mouse models, several conceptual frameworks have emerged that may help understand the pathophysiology of human mental conditions. First, these models highlighted several relevant cell types that are aberrantly regulated, including astrocytes (Abazyan et al., 2014), oligodendrocytes (Katsel et al., 2011), and CA1 pyramidal neurons (Booth et al., 2014), in addition to widely studied output and interneurons in the prefrontal cortex. Thus, roles for neuron-glia interaction in the pathology of mental illness may be tested in these models.

Second, the DN-DISC1 approach revealed a developmentally critical period in which sensory experience affects cortical development and plasticity (Greenhill et al., 2015). Transient disruption of DISC1 function during a neonatal period disrupted LTP/LTD later in adulthood, providing a basis for cognitive impairment and its delayed onset in human psychiatric conditions. This study has conceptually extended a previous study in which the influence of transient knockdown of DISC1 in the developing cortex on adult behavioral deficits was reported (Niwa et al., 2010). Both studies indicate that DISC1 plays a crucial role for adult brain function and behaviors by influencing developmental trajectories in several critical periods.

Third, the DN-DISC1 transgenic approach has linked prefrontal cortex-specific elevation of oxidative stress to deficits in cognitive and motivational behavioral paradigms, as measured by tasks, such as the reversal learning and reinforcer devaluation paradigms (Johnson et al., 2013). Oxidative stress can be elicited by a combination of environmental stress and genetic insults, and thus provide a useful cell biological readout to evaluate the levels of stress caused as a result of host-environmental 
interaction, as will be discussed later.

Finally, many of these studies implicated significant alterations in key neurotransmitter systems, including glutamatergic, dopaminergic, cannabinoid, or nicotinic neurotransmission (Jaaro-Peled et al., 2013; Kaminitz et al., 2014; Ballinger et al., 2015; Dawson et al., 2015; Kim et al., 2015). Taken together, these transgenic approaches, coupled with DN-DISC1 constructs, are expected to further contribute to the understanding of pathobiology associated with human psychiatric conditions (Table 1).

\section{Host-environment interactions}

Approximately one-third of the family members carrying the DISCI breakpoint mutation reportedly manifest with some aspects of mental conditions (Blackwood et al., 2001). In addition, a critical finding that emerged after generation of a series of Discl mouse models was that not a single model displayed a full-blown spectrum of behavioral and cognitive deficits. These observations suggested that the host perturbation elicited by a Discl locus mutation is prone to developing neurocognitive dysfunctions when an additional environmental or genetic insult occurs. A series of environmental stress paradigms have been applied to Discl mouse models to test host-environment interactions possibly for mental conditions. These stress paradigms include maternal immune activation by polyI:C injection at embryonic day 9 (Abazyan et al., 2010; Lipina et al., 2013), neonatal immune activation by polyI:C injection at postnatal days 2-6, which corresponds to the second trimester of human brain development (Ibi et al., 2010; Nagai et al., 2011), chronic social defeat (Haque et al., 2012), and adolescent social isolation stress (Niwa et al., 2013), as previously reviewed (Cash-Padgett and Jaaro-Peled, 2013).

In addition, recent reports addressed an effect of exposure to lead (Abazyan et al., 2013), as well as to cannabis (Ballinger et al., 2015), in DN-DISC1 mouse models. When mice were exposed to lead in diet from conception throughout life, the volume of the lateral ventricle was significantly increased only in female DN-DISC1 mice, but not in males or the wild-type controls (Abazyan et al., 2013). Lead exposure in DN-DISC1 male mice increased the peripheral activity in the open field box, while decreasing it in control males. DN-DISC1 mice also showed a greater response to the psychostimulant MK-801 than control mice. Furthermore, DN-DISC1 female mice had a PPI deficit when exposed to lead, whereas the control mice and DN-DISC1 male mice did not. These observations present a sexdependent, and a task-dependent example of interaction between Disc1 dysfunction and the environmental toxin.

Cannabis use, especially in adolescence, is known to increase the risk of psychosis, but the underlying mechanisms remain elusive (Andreasson et al., 1987; Arseneault et al., 2002; Henquet et al., 2005; van Os et al., 2002). Mice injected with a cannabinoid $\Delta^{9}$-THC from four through seven weeks of age had lower levels of synaptosomal cannabinoid receptor 1 expression, comparable to that in DN- 
DISC1 mice (Ballinger et al., 2015). In a cued fear conditioning test, exposure to $\Delta^{9}$-THC produced a deficit only in DN-DISC1, but not in wild-type mice. Accordingly, DN-DISC1 mice exposed to $\Delta^{9}$-THC showed a smaller increase in c-Fos immunostaining than wild-type, suggesting a lower neuronal activation in DN-DISC1 mice in response to the cue. The finding suggests a role of DISC1 in the development of cannabis-mediated psychosis.

Taken together, DISC1 mouse models have provided valuable opportunities to test various aspects of host-environment interaction underlying mental illnesses.

\section{Enigma}

It remains an enigma as to why the phenotypes observed in Discl haploinsufficiency models are generally smaller than those seen for Discl point mutation or DN models. One plausible reason is that the phenotypes resulting from depletion of some Discl isoforms, including major full-length isoforms, could be masked due to developmental compensation mechanisms. For example, defects in neuronal proliferation during cortical development can be overcome in part by compensatory adjustments by surrounding cell populations other than neurons. Delay in neuronal migration could also be compensated by prolonged migration over time.

Alternatively, complexity in the expression of multiple DISC1 isoforms, as well as functional heterogeneity of DISC1 proteins may provide a key to understand this enigma. Although a number of DISC1 isoforms have been identified at the transcript level (Nakata et al., 2009), we do not yet know the full spectrum of transcriptional landscape of the DISC1 gene, as well as the functional properties of each isoform. For instance, exons $2 / 3$ were deleted in $\Delta \mathrm{ex} 2 / 3$ model as initially designed, but the downstream exons 7 through 11 are still expressed in this model (Kuroda et al., 2011). Given that an intergenic splicing event has been reported for DISC1 and the upstream neighboring gene TSNAX (Millar et al., 2000; Li et al., 2014), possible expression of chimeric proteins spanning TSNAX and DISC1 (exons 7-11) may influence mutant phenotypes in mice. Likewise, $\Delta 25 \mathrm{bp}$ mouse model is reported to express a shorter Disc1 isoform (Kvajo et al., 2008), which resembles a C-terminally truncated DN-DISC1, and could thus function in a dominant-negative manner or may have a yet uncharacterized functional property. Although the half-life of this shorter Disc1 isoform appears short and its expression level low, potential effects of transient expression of various Discl isoforms should be taken into account in interpreting the mutant phenotypes. Transient expression of DN-DISC1 during a neonatal stage apparently impacted neuroplasticity later in adulthood (Greenhill et al., 2015), similar to transient knockdown of DISC1 that impacts neuropharmacological and behavioral characteristics in adulthood (Niwa et al, 2010).

To solve these enigmas, detailed characterization of transcriptional and translational regulation at 
Discl locus in particular, as well as across the entire genome, will be necessary. In this regard, we propose to carry out RNA-Seq analysis of the whole transcriptome of multiple Discl mouse models. Additional strategies to address these enigmas are summarized in Table 2.

\section{Discussion and future perspectives}

As outlined above, DISC1 mutant mice have proven useful in modeling multiple dimensions of behavioral outcomes that are relevant to human mental conditions. Contrary to the initial expectation, as reflected by its name, DISC1 should not be considered as a gene causative for schizophrenia. Recent advances in human genetic studies have made it clear that multiple diagnostic entities of mental illnesses are caused by dysfunction of overlapping sets of genes (Huang et al., 2010; Lee et al., 2012; Network and Pathway Analysis Subgroup of Psychiatric Genomics Consortium, 2015). Likewise, DISC1 deregulation is linked to multiple mental conditions beyond conventional diagnostic boundaries defined by the Diagnostic and Statistical Manual of Mental Disorders (DSM) (Brandon and Sawa, 2011).

At least at present, we cannot look for the etiological validity of each DISC1 model by a clear-cut genetic mutation associated with single DSM-classified mental disorder. This is not so surprising given that the disruption of the gene is tightly associated with the alteration of an endophenotype (event related potential P300) that underlies multiple mental conditions beyond the DSM classification (Blackwood et al., 2001). Instead, we can stand more on the face validity of each behavioral dimension that is associated with molecular changes in the pathways involving DISC1. It is scientifically productive and valid to explore the biology that links molecular cascades to behaviors via cellular and circuitry mechanisms. This discussion is consistent with a recent proposal by the Research Domain Criteria (RDoC), in which molecular signatures are hypothesized to underlie physiological and behavioral characteristics, rather than disease entities categorized by operational diagnostic criteria, such as DSM (Insel et al., 2010; Cuthbert and Insel, 2013; Insel, 2014).

Genome-wide studies of psychiatric genetics have provided candidate loci for schizophrenia and other mental disorders, which include several promising genes (Fromer et al., 2014; Purcell et al., 2014; Schizophrenia Working Group of the Psychiatric Genomics Consortium, 2014). DISC1 is associated with some of these molecules via direct protein interactions or functional/pharmacological interactions. In addition, administration of a p21-activated kinase (PAK) inhibitor ameliorates spine deficits and behavioral abnormalities elicited by DISC1 knockdown (Hayashi-Takagi et al., 2014). Interestingly, the same inhibitor also ameliorates the behavioral deficits of mice deficient for the Fmrl gene (Dolan et al., 2013), recently indicated to be the most promising risk gene for schizophrenia (Fromer et al., 2014; Purcell et al., 2014).

Because DISC1 protein can be subdivided into a series of subdomains, each of which physically 
interacts with specific binding partners, we could functionally dissect DISC1 into subdomains that are responsible for achieving certain behavioral or cognitive tasks. We could utilize such structure-function information (e.g., DISC1-D2R interaction) in the design of novel therapeutic approaches, in which specific interference of DISC1 binding with its partners could improve functional outcomes without showing severe side effects such as catalepsy (Su et al., 2014).

Human DISCl breakpoint mutation has been reported to generate fusion proteins by spanning over chromosome 1 and 11, generating aggregation-prone protein species (Zhou et al., 2010; Ji et al, 2014; Ji et al., 2015). Similarly, recent studies demonstrated that DISC1 protein is prone to selfaggregation or co-aggregation with other proteins such as dysbindin (Leliveld et al., 2008; Ottis et al., 2011; Atkin et al., 2012), likely due to impairment of the protein quality control or cellular clearance systems. It remains to be studied how these aggregated species of DISC1 are generated along the developmental trajectories or in response to genetic and environmental insults. DISC1 mouse models are expected to provide mechanistic insight into these questions, as well as behavioral outcomes relevant to psychiatric conditions.

Deeper in the brain, we are likely to find more precise mechanisms underlying functional disturbances in DISC1 mouse models at the cellular level. DISC1 is expressed not only in neurons but also in glial cells (Seshadri et al, 2010). Emerging data are beginning to point to the role of glia (e.g., astrocyte, oligodendrocyte, microglia), or of neuron-glia interaction in the pathophysiology of DISC1 dysfunction (Katsel et al., 2011; Abazyan et al., 2014).

Given the ample information on a series of behavioral disturbances described for these models, we could analyze in further detail mechanisms underlying defective behavioral or cognitive dimensions at the circuit level. For example, a deficit in PPI found in some of the DISC1 mice could be studied in order to understand neural circuitries responsible for sensorimotor information processing. Using modern techniques of systems neuroscience, coupled with magnetic resonance imaging and other brain imaging techniques, one could analyze circuit-level disturbances in DISC1 mouse models. We anticipate identifying key deficits in circuitry in these models, and will validate the findings by comparing with functional imaging data from patients with mental disorders. In parallel, optogenetics and in vivo electrophysiological recording approaches in mice will prove the link of a specific circuit to a given functional outcome, and could also be used to test the efficacy of therapeutic agents. In addition, the Human Connectome Project will help build a model useful for understanding global network disturbance in psychiatric disorders (Deco and Kringelbach, 2014). Mouse models could provide a test case for experimental validation of theoretical ideas generated through human brain imaging and genetic studies (Owen et al., 2015; Landek-Salgado et al., 2015).

Once such mechanisms (either molecular, cellular, or circuit-level) that likely underlie 
pathophysiology of each behavioral dimension that constitutes human mental conditions are corroborated using these DISC1 mouse models, we could validate whether they can be used as biomarkers useful for diagnosis, or targets for therapeutic intervention. For instance, reduction in neuronal progenitor proliferation, associated with elevated GSK3 $\beta$ activity, was observed in Disc1 knockdown mice, and GSK3 $\beta$ inhibition successfully ameliorated these molecular, cellular, and behavioral deficits, including hyperlocomotion (Mao et al., 2009). Subsequent work using the point mutation Disc1 models also showed therapeutic effects of GSK3 $\beta$ inhibitors (Lipina et al., 2012a), identified a potential new drug target (Lipina et al., 2012b), as well as a novel therapeutic strategy via inhibition of D2R-DISC1 interaction (Su et al., 2014). Additionally, dendritic spine deterioration, caused by elevated PAK activation, was found in Discl knockdown mice, and novel PAK inhibitors were shown to ameliorate the cellular and the associated behavioral deficits (Hayashi-Takagi et al., 2014). Thus, DISC1 mouse models are expected to continue providing platform to test ideas for novel diagnostic and therapeutic avenues for combating mental illnesses. 


\section{Acknowledgments}

We thank Dr. Tom Macpherson for critical reading of the manuscript. We also thank Ms. Yukiko Lema for manuscript and figure preparation. The present study was supported by the NIH (MH-084018, MH094268 Silvio O. Conte Center, MH-069853, MH-085226, MH-088753, and MH-092443 to A.S.);

grants from Stanley, S-R, RUSK, NARSAD, and Maryland Stem Cell Research Fund (A.S.); and by the DOD/CDMRP (W81XWH-11-1-0269 to T.T.). In addition, the present study was partly supported by Takeda Pharmaceutical Co. Ltd at the Kyoto University. 


\section{Legend for Figure 1.}

This diagram summarizes how DISC1 elicits its functions at the molecular and cellular levels, leading to modulation of a series of neurotransmitter systems, as well as neural circuitry, which ultimately determine a range of behavioral domains, such as emotion and cognition. Deregulated DISC1 function primarily leads to impairment of neuronal development, signaling, and synaptic activities, which, coupled with various environmental insults, further affect neurotransmitter systems and neural circuitry, leading to manifestation of behavioral abnormalities.

Dimensional characterization of a range of research domains affected by DISC1 dysfunction will help understand the pathophysiological mechanisms underlying human psychiatric conditions.

Note that, in essence, DISC1 should not be synonymous with the gene disrupted in schizophrenia; it should rather be recognized as a gene disrupted in system connectivity. 


\section{References}

Abazyan B, Dziedzic J, Hua K, Abazyan S, Yang C, Mori S, Pletnikov MV, Guilarte TR (2014a) Chronic exposure of mutant DISC1 mice to lead produces sex-dependent abnormalities consistent with schizophrenia and related mental disorders: a gene-environment interaction study. Schizophr Bull 40:575-584.

Abazyan B, Nomura J, Kannan G, Ishizuka K, Tamashiro KL, Nucifora F, Pogorelov V, Ladenheim B, Yang C, Krasnova IN, Cadet JL, Pardo C, Mori S, Kamiya A, Vogel MW, Sawa A, Ross CA, Pletnikov MV (2010) Prenatal interaction of mutant DISC1 and immune activation produces adult psychopathology. Biol Psychiatry 68:1172-1181.

Abazyan S, Yang EJ, Abazyan B, Xia M, Yang C, Rojas C, Slusher B, Sattler R, Pletnikov M (2014b) Mutant disrupted-in-schizophrenia 1 in astrocytes: focus on glutamate metabolism. J Neurosci Res 92:1659-1668.

Andréasson S, Allebeck P, Engström A, Rydberg U (1987) Cannabis and schizophrenia. A longitudinal study of Swedish conscripts. Lancet 2:1483-1486.

Arseneault L, Cannon M, Poulton R, Murray R, Caspi A, Moffitt TE (2002) Cannabis use in adolescence and risk for adult psychosis: longitudinal prospective study. BMJ 325:1212-1213.

Atkin TA, Brandon NJ, Kittler JT (2012) Disrupted in Schizophrenia 1 forms pathological aggresomes that disrupt its function in intracellular transport. Hum Mol Genet 21:2017-2028.

Ballinger MD, Saito A, Abazyan B, Taniguchi Y, Huang CH, Ito K, Zhu X, Segal H, Jaaro-Peled H, Sawa A, Mackie K, Pletnikov MV, Kamiya A (2015) Adolescent cannabis exposure interacts with mutant DISC1 to produce impaired adult emotional memory. Neurobiol of Disease 82:176184.

Blackwood DH, Fordyce A, Walker MT, St Clair DM, Porteous DJ, Muir WJ (2001) Schizophrenia and affective disorders--cosegregation with a translocation at chromosome 1q42 that directly disrupts brain-expressed genes: clinical and P300 findings in a family. Am J Hum Genet 69:428-433.

Booth CA, Brown JT, Randall AD (2014) Neurophysiological modification of CA1 pyramidal neurons in a transgenic mouse expressing a truncated form of disrupted-in-schizophrenia 1. Eur J Neurosci 39:1074-1090.

Brandon NJ, Sawa A (2011) Linking neurodevelopmental and synaptic theories of mental illness through DISC1. Nature Rev Neurosci 12:707-722.

Brown SM, Clapcote SJ, Millar JK, Torrance HS, Anderson SM, Walker R, Rampino A, Roder JC, Thomson PA, Porteous DJ, Evans KL (2011) Synaptic modulators Nrxn1 and Nrxn3 are disregulated in a Disc1 mouse model of schizophrenia. Mol Psychiatry 16:585-587.

Cash-Padgett T, Jaaro-Peled H (2013) DISC1 mouse models as a tool to decipher gene-environment 
interactions in psychiatric disorders. Frontiers Behav Neurosci 7:113.

Clapcote SJ, Lipina TV, Millar JK, Mackie S, Christie S, Ogawa F, Lerch JP, Trimble K, Uchiyama M,

Sakuraba Y, Kaneda H, Shiroishi T, Houslay MD, Henkelman RM, Sled JG, Gondo Y, Porteous

DJ, Roder JC (2007) Behavioral phenotypes of Disc1 missense mutations in mice. Neuron 54:387-402.

Cross-Disorder Group of the Psychiatric Genomics Consortium (2013) Genetic relationship between

five psychiatric disorders estimated from genome-wide SNPs. Nat Genet 45:984-994.

Cuthbert BN, Insel TR (2013) Toward the future of psychiatric diagnosis: the seven pillars of RDoC.

BMC Med 11:126.

Dawson N, Kurihara M, Thomson DM, Winchester CL, McVie A, Hedde JR, Randall AD, Shen S, Seymour PA, Hughes ZA, Dunlop J, Brown JT, Brandon NJ, Morris BJ, Pratt JA (2015) Altered functional brain network connectivity and glutamate system function in transgenic mice expressing truncated Disrupted-in-Schizophrenia 1. Transl Psychiatry 5:e569.

Deco G, Kringelbach ML (2014) Great expectations: using whole-brain computational connectomics for understanding neuropsychiatric disorders. Neuron 84:892-905.

Dolan BM, Duron SG, Campbell DA, Vollrath B, Shankaranarayana Rao BS, Ko HY, Lin GG, Govindarajan A, Choi SY, Tonegawa S (2013) Rescue of fragile X syndrome phenotypes in Fmrl KO mice by the small-molecule PAK inhibitor FRAX486. Proc Natl Acad Sci U S A 110:5671-5676.

Fromer M, Pocklington AJ, Kavanagh DH, Williams HJ, Dwyer S, Gormley P, Georgieva L, Rees E, Palta P, Ruderfer DM, Carrera N, Humphreys I, Johnson JS, Roussos P, Barker DD, Banks E, Milanova V, Grant SG, Hannon E, Rose SA, Chambert K, Mahajan M, Scolnick EM, Moran JL, Kirov G, Palotie A, McCarroll SA, Holmans P, Sklar P, Owen MJ, Purcell SM, O'Donovan MC (2014) De novo mutations in schizophrenia implicate synaptic networks. Nature 506:179-184. Greenhill SD, Juczewski K, de Haan AM, Seaton G, Fox K, Hardingham NR (2015) Adult cortical plasticity depends on an early postnatal critical period. Science 349:424-427.

Haque FN, Lipina TV, Roder JC, Wong AH (2012) Social defeat interacts with Disc1 mutations in the mouse to affect behavior. Behav Brain Res 233:337-344.

Hayashi-Takagi A, Takaki M, Graziane N, Seshadri S, Murdoch H, Dunlop AJ, Makino Y, Seshadri AJ, Ishizuka K, Srivastava DP, Xie Z, Baraban JM, Houslay MD, Tomoda T, Brandon NJ, Kamiya A, Yan Z, Penzes P, Sawa A (2010) Disrupted-in-Schizophrenia 1 (DISC1) regulates spines of the glutamate synapse via Rac1. Nature Neurosci 13:327-332.

Hayashi-Takagi A, Araki Y, Nakamura M, Vollrath B, Duron SG, Yan Z, Kasai H, Huganir RL, Campbell DA, Sawa A (2014) PAKs inhibitors ameliorate schizophrenia-associated dendritic 
spine deterioration in vitro and in vivo during late adolescence. Proc Natl Acad Sci U S A 111:6461-6466.

Henquet C, Krabbendam L, Spauwen J, Kaplan C, Lieb R, Wittchen HU, van Os J (2005) Prospective cohort study of cannabis use, predisposition for psychosis, and psychotic symptoms in young people. BMJ 330:11.

Hikida T, Jaaro-Peled H, Seshadri S, Oishi K, Hookway C, Kong S, Wu D, Xue R, Andrade M, Tankou S, Mori S, Gallagher M, Ishizuka K, Pletnikov M, Kida S, Sawa A (2007) Dominant-negative DISC1 transgenic mice display schizophrenia-associated phenotypes detected by measures translatable to humans. Proc Natl Acad Sci U S A 104:14501-14506.

Hikida T, Gamo NJ, Sawa A (2012) DISC1 as a therapeutic target for mental illnesses. Expert Opin Ther Targets 16:1151-1160.

Huang J, Perlis RH, Lee PH, Rush AJ, Fava M, Sachs GS, Lieberman J, Hamilton SP, Sullivan P, Sklar P, Purcell S, Smoller JW (2010) Cross-disorder genome-wide analysis of schizophrenia, bipolar disorder, and depression. Am J Psychiatry 167:1254-1263.

Ibi D, Nagai T, Koike H, Kitahara Y, Mizoguchi H, Niwa M, Jaaro-Peled H, Nitta A, Yoneda Y, Nabeshima T, Sawa A, Yamada K (2010) Combined effect of neonatal immune activation and mutant DISC1 on phenotypic changes in adulthood. Behav Brain Res 206:32-37.

Ikeda M, Aleksic B, Kinoshita Y, Okochi T, Kawashima K, Kushima I, Ito Y, Nakamura Y, Kishi T, Okumura T, Fukuo Y, Williams HJ, Hamshere ML, Ivanov D, Inada T, Suzuki M, Hashimoto R, Ujike H, Takeda M, Craddock N, Kaibuchi K, Owen MJ, Ozaki N, O'Donovan MC, Iwata N (2011) Genome-wide association study of schizophrenia in a Japanese population. Biol Psychiatry 69: 472-478.

Insel T, Cuthbert B, Garvey M, Heinssen R, Pine DS, Quinn K, Sanislow C, Wang P (2010) Research domain criteria (RDoC): toward a new classification framework for research on mental disorders. Am J Psychiatry 167:748-751.

Insel TR (2014) The NIMH Research Domain Criteria (RDoC) Project: precision medicine for psychiatry. Am J Psychiatry 171:395-397.

Ishizuka K, Kamiya A, Oh EC, Kanki H, Seshadri S, Robinson JF, Murdoch H, Dunlop AJ, Kubo K, Furukori K, Huang B, Zeledon M, Hayashi-Takagi A, Okano H, Nakajima K, Houslay MD, Katsanis N, Sawa A (2011) DISC1-dependent switch from progenitor proliferation to migration in the developing cortex. Nature 473:92-96.

Jaaro-Peled H, Niwa M, Foss CA, Murai R, de Los Reyes S, Kamiya A, Mateo Y, O'Donnell P, Cascella NG, Nabeshima T, Guilarte TR, Pomper MG, Sawa A (2013) Subcortical dopaminergic deficits in a DISC1 mutant model: a study in direct reference to human molecular brain imaging. Hum 
Mol Genet 22:1574-1580.

Ji B, Higa KK, Kim M, Zhou L, Young JW, Geyer MA, Zhou X (2014) Inhibition of protein translation by the DISC1-Boymaw fusion gene from a Scottish family with major psychiatric disorders. Hum Mol Genet 23:5683-5705.

Ji B, Kim M, Higa KK, Zhou X (2015) Boymaw, overexpressed in brains with major psychiatric disorders, may encode a small protein to inhibit mitochondrial function and protein translation. Am J Med Genet B Neuropsychiatr Genet 168B:284-295.

Johnson AW, Jaaro-Peled H, Shahani N, Sedlak TW, Zoubovsky S, Burruss D, Emiliani F, Sawa A, Gallagher M (2013) Cognitive and motivational deficits together with prefrontal oxidative stress in a mouse model for neuropsychiatric illness. Proc Natl Acad Sci U S A 110:12462-12467.

Juan LW, Liao CC, Lai WS, Chang CY, Pei JC, Wong WR, Liu CM, Hwu HG, Lee LJ (2014) Phenotypic characterization of C57BL/6J mice carrying the Disc1 gene from the 129S6/SvEv strain. Brain Structure \& Function 219:1417-1431.

Kaminitz A, Barzilay R, Segal H, Taler M, Offen D, Gil-Ad I, Mechoulam R, Weizman A (2014) Dominant negative DISC1 mutant mice display specific social behaviour deficits and aberration in BDNF and cannabinoid receptor expression. World J Biol Psychiatry 15:76-82.

Kamiya A, Kubo K, Tomoda T, Takaki M, Youn R, Ozeki Y, Sawamura N, Park U, Kudo C, Okawa M, Ross CA, Hatten ME, Nakajima K, Sawa A (2005) A schizophrenia-associated mutation of DISC1 perturbs cerebral cortex development. Nat Cell Biol 7:1167-1178.

Katsel P, Tan W, Abazyan B, Davis KL, Ross C, Pletnikov MV, Haroutunian V (2011) Expression of mutant human DISC1 in mice supports abnormalities in differentiation of oligodendrocytes. Schizophr Res 130:238-249.

Kim J, Horti AG, Mathews WB, Pogorelov V, Valentine H, Brasic JR, Holt DP, Ravert HT, Dannals RF, Zhou L, Jedynak B, Kamiya A, Pletnikov MV, Wong DF (2015) Quantitative Multi-modal Brain Autoradiography of Glutamatergic, Dopaminergic, Cannabinoid, and Nicotinic Receptors in Mutant Disrupted-In-Schizophrenia-1 (DISC1) Mice. Mol Imaging Biol 17:355-363.

Koike H, Arguello PA, Kvajo M, Karayiorgou M, Gogos JA (2006) Disc1 is mutated in the 129S6/SvEv strain and modulates working memory in mice. Proc Natl Acad Sci U S A 103:3693-3697.

Kranz TM, Harroch S, Manor O, Lichtenberg P, Friedlander Y, Seandel M, Harkavy-Friedman J, WalshMessinger J, Dolgalev I, Heguy A, Chao MV, Malaspina D (2015) De novo mutations from sporadic schizophrenia cases highlight important signaling genes in an independent sample. Schizophr Res 166:119-124.

Krüger L, Mandelkow EM (2015) Tau neurotoxicity and rescue in animal models of human Tauopathies. Curr Opin Neurobiol 36:52-58. 
Kuroda K, Yamada S, Tanaka M, lizuka M, Yano H, Mori D, Tsuboi D, Nishioka T, Namba T, lizuka Y, Kubota S, Nagai T, Ibi D, Wang R, Enomoto A, Isotani-Sakakibara M, Asai N, Kimura K, Kiyonari H, Abe T, Mizoguchi A, Sokabe M, Takahashi M, Yamada K, Kaibuchi K (2011) Behavioral alterations associated with targeted disruption of exons 2 and 3 of the Disc 1 gene in the mouse. Hum Mol Genet 20:4666-4683.

Kushima I, Nakamura Y, Aleksic B, Ikeda M, Ito Y, Shiino T, Okochi T, Fukuo Y, Ujike H, Suzuki M, Inada T, Hashimoto R, Takeda M, Kaibuchi K, Iwata N, Ozaki N (2012) Resequencing and association analysis of the KALRN and EPHB1 genes and their contribution to schizophrenia susceptibility. Schizophr Bull 38:552-560.

Kvajo M, McKellar H, Arguello PA, Drew LJ, Moore H, MacDermott AB, Karayiorgou M, Gogos JA (2008) A mutation in mouse Disc1 that models a schizophrenia risk allele leads to specific alterations in neuronal architecture and cognition. Proc Natl Acad Sci U S A 105:7076-7081.

Kvajo M, McKellar H, Drew LJ, Lepagnol-Bestel AM, Xiao L, Levy RJ, Blazeski R, Arguello PA, Lacefield CO, Mason CA, Simonneau M, O'Donnell JM, MacDermott AB, Karayiorgou M, Gogos JA (2011) Altered axonal targeting and short-term plasticity in the hippocampus of Disc1 mutant mice. Proc Natl Acad Sci U S A 108:E1349-1358.

Landek-Salgado MA, Faust TE, Sawa A (2015) Molecular substrates of schizophrenia: homeostatic signaling to connectivity. Mol Psychiatry advance online publication, 22 September 2015; doi:10.1038/mp.2015.141.

Lee FH, Fadel MP, Preston-Maher K, Cordes SP, Clapcote SJ, Price DJ, Roder JC, Wong AH (2011) Disc1 point mutations in mice affect development of the cerebral cortex. J Neurosci 31:31973206.

Lee FH, Kaidanovich-Beilin O, Roder JC, Woodgett JR, Wong AH (2011) Genetic inactivation of GSK3alpha rescues spine deficits in Disc1-L100P mutant mice. Schizophr Res 129:74-79.

Lee FH, Zai CC, Cordes SP, Roder JC, Wong AH (2013) Abnormal interneuron development in disrupted-in-schizophrenia-1 L100P mutant mice. Mol Brain 6:20.

Lee KW, Woon PS, Teo YY, Sim K (2012) Genome wide association studies (GWAS) and copy number variation (CNV) studies of the major psychoses: what have we learnt? Neurosci Biobehav Rev 36:556-571.

Leliveld SR, Bader V, Hendriks P, Prikulis I, Sajnani G, Requena JR, Korth C (2008) Insolubility of disrupted-in-schizophrenia 1 disrupts oligomer-dependent interactions with nuclear distribution element 1 and is associated with sporadic mental disease. J Neurosci 28:3839-3845.

Lepagnol-Bestel AM, Kvajo M, Karayiorgou M, Simonneau M, Gogos JA (2013) A Disc1 mutation differentially affects neurites and spines in hippocampal and cortical neurons. Mol Cell Neurosci 
54:84-92.

Li N, Zheng J, Li H, Deng J, Hu M, Wu H, Li W, Li F, Lan X, Lu J, Zhou Y (2014) Identification of chimeric TSNAX-DISC1 resulting from intergenic splicing in endometrial carcinoma through high-throughput RNA sequencing. Carcinogenesis 35:2687-2697.

Li W, Zhou Y, Jentsch JD, Brown RA, Tian X, Ehninger D, Hennah W, Peltonen L, Lonnqvist J, Huttunen MO, Kaprio J, Trachtenberg JT, Silva AJ, Cannon TD (2007) Specific developmental disruption of disrupted-in-schizophrenia-1 function results in schizophrenia-related phenotypes in mice. Proc Natl Acad Sci U S A 104:18280-18285.

Lipina TV, Niwa M, Jaaro-Peled H, Fletcher PJ, Seeman P, Sawa A, Roder JC (2010) Enhanced dopamine function in DISC1-L100P mutant mice: implications for schizophrenia. Genes Brain Behav 9:777-789.

Lipina TV, Wang M, Liu F, Roder JC (2012a) Synergistic interactions between PDE4B and GSK-3: DISC1 mutant mice. Neuropharmacol 62:1252-1262.

Lipina TV, Haque FN, McGirr A, Boutros PC, Berger T, Mak TW, Roder JC, Wong AH (2012b) Prophylactic valproic acid treatment prevents schizophrenia-related behaviour in Disc1-L100P mutant mice. PLoS One 7:e51562.

Lipina TV, Zai C, Hlousek D, Roder JC, Wong AH (2013) Maternal immune activation during gestation interacts with Disc1 point mutation to exacerbate schizophrenia-related behaviors in mice. $\mathrm{J}$ Neurosci 33:7654-7666.

Mao Y, Ge X, Frank CL, Madison JM, Koehler AN, Doud MK, Tassa C, Berry EM, Soda T, Singh KK, Biechele T, Petryshen TL, Moon RT, Haggarty SJ, Tsai LH (2009) Disrupted in schizophrenia 1 regulates neuronal progenitor proliferation via modulation of GSK3beta/beta-catenin signaling. Cell 136:1017-1031.

Mathieson I, Munafò MR, Flint J (2012) Meta-analysis indicates that common variants at the DISC1 locus are not associated with schizophrenia. Mol Psychiatry 17:634-641.

Millar JK, Wilson-Annan JC, Anderson S, Christie S, Taylor MS, Semple CA, Devon RS, St Clair DM, Muir WJ, Blackwood DH, Porteous DJ (2000) Disruption of two novel genes by a translocation co-segregating with schizophrenia. Hum Mol Genet 9:1415-1423.

Millar JK, Christie S, Semple CA, Porteous DJ (2000) Chromosomal location and genomic structure of the human translin-associated factor X gene (TRAX; TSNAX) revealed by intergenic splicing to DISC1, a gene disrupted by a translocation segregating with schizophrenia. Genomics 67:69-77.

Muraki K, Tanigaki K (2015) Neuronal migration abnormalities and its possible implications for schizophrenia. Front Neurosci 9:74.

Nagai T, Kitahara Y, Ibi D, Nabeshima T, Sawa A, Yamada K (2011) Effects of antipsychotics on the 
behavioral deficits in human dominant-negative DISC1 transgenic mice with neonatal polyI:C treatment. Behav Brain Res 225:305-310.

Nakai T, Nagai T, Wang R, Yamada S, Kuroda K, Kaibuchi K, Yamada K (2014) Alterations of GABAergic and dopaminergic systems in mutant mice with disruption of exons 2 and 3 of the Disc1 gene. Neurochem Intl 74:74-83.

Nakata K, Lipska BK, Hyde TM, Ye T, Newburn EN, Morita Y, Vakkalanka R, Barenboim M, Sei Y, Weinberger DR, Kleinman JE (2009) DISC1 splice variants are upregulated in schizophrenia and associated with risk polymorphisms. Proc Natl Acad Sci U S A 106:15873-15878.

Narayan S, Nakajima K, Sawa A (2013) DISC1: a key lead in studying cortical development and associated brain disorders. Neuroscientist 19:451-464.

Network and Pathway Analysis Subgroup of Psychiatric Genomics Consortium (2015) Psychiatric genome-wide association study analyses implicate neuronal, immune and histone pathways. Nature Neurosci 18:199-209.

Niwa M, Kamiya A, Murai R, Kubo K, Gruber AJ, Tomita K, Lu L, Tomisato S, Jaaro-Peled H, Seshadri S, Hiyama H, Huang B, Kohda K, Noda Y, O'Donnell P, Nakajima K, Sawa A, Nabeshima T (2010) Knockdown of DISC1 by in utero gene transfer disturbs postnatal dopaminergic maturation in the frontal cortex and leads to adult behavioral deficits. Neuron 65:480-489.

Niwa M, Jaaro-Peled H, Tankou S, Seshadri S, Hikida T, Matsumoto Y, Cascella NG, Kano S, Ozaki N, Nabeshima T, Sawa A (2013) Adolescent stress-induced epigenetic control of dopaminergic neurons via glucocorticoids. Science 339:335-339.

Ottis P, Bader V, Trossbach SV, Kretzschmar H, Michel M, Leliveld SR, Korth C (2011) Convergence of two independent mental disease genes on the protein level: recruitment of dysbindin to cellinvasive disrupted-in-schizophrenia 1 aggresomes. Biol Psychiatry 70:604-610.

Owen MJ, Sawa A, Mortensen PB (2015) Schizophrenia. Lancet (in press)

Park SJ, Jeong J, Park YU, Park KS, Lee H, Lee N, Kim SM, Kuroda K, Nguyen MD, Kaibuchi K, Park SK (2015) Disrupted-in-schizophrenia-1 (DISC1) Regulates Endoplasmic Reticulum Calcium Dynamics. Sci Rep 5:8694.

Piaceri I, Nacmias B, Sorbi S (2013) Genetics of familial and sporadic Alzheimer's disease. Front Biosci $5: 167-177$.

Pletnikov MV, Ayhan Y, Nikolskaia O, Xu Y, Ovanesov MV, Huang H, Mori S, Moran TH, Ross CA (2008) Inducible expression of mutant human DISC1 in mice is associated with brain and behavioral abnormalities reminiscent of schizophrenia. Mol Psychiatry 13:173-186.

Porteous DJ, Millar JK, Brandon NJ, Sawa A (2011) DISC1 at 10: connecting psychiatric genetics and neuroscience. Trends Mol Med 17:699-706. 
Potkin SG, Turner JA, Guffanti G, Lakatos A, Fallon JH, Nguyen DD, Mathalon D, Ford J, Lauriello J, Macciardi F; FBIRN (2009) A genome-wide association study of schizophrenia using brain activation as a quantitative phenotype. Schizophr Bull 35:96-108.

Purcell SM, Wray NR, Stone JL, Visscher PM, O'Donovan MC, Sullivan PF, Sklar P (2009) Common polygenic variation contributes to risk of schizophrenia and bipolar disorder. Nature 460:748752.

Purcell SM, Moran JL, Fromer M, Ruderfer D, Solovieff N, Roussos P, O'Dushlaine C, Chambert K, Bergen SE, Kähler A, et al. (2014) A polygenic burden of rare disruptive mutations in schizophrenia. Nature 506:185-190.

Ripke S, O'Dushlaine C, Chambert K, Moran JL, Kähler AK, Akterin S, Bergen SE, Collins AL, Crowley JJ, Fromer M, et al. (2013) Genome-wide association analysis identifies 13 new risk loci for schizophrenia. Nat Genet 45:1150-1159.

Schizophrenia Working Group of the Psychiatric Genomics Consortium (2014) Biological insights from 108 schizophrenia-associated genetic loci. Nature 511:421-427.

Seshadri S, Kamiya A, Yokota Y, Prikulis I, Kano S, Hayashi-Takagi A, Stanco A, Eom TY, Rao S, Ishizuka K, Wong P, Korth C, Anton ES, Sawa A (2010) Disrupted-in-Schizophrenia-1 expression is regulated by beta-site amyloid precursor protein cleaving enzyme-1-neuregulin cascade. Proc Natl Acad Sci U S A 107:5622-5627.

Shahani N, Seshadri S, Jaaro-Peled H, Ishizuka K, Hirota-Tsuyada Y, Wang Q, Koga M, Sedlak TW, Korth C, Brandon NJ, Kamiya A, Subramaniam S, Tomoda T, Sawa A (2015) DISC1 regulates trafficking and processing of APP and Abeta generation. Mol Psychiatry 20:874-879.

Shen S, Lang B, Nakamoto C, Zhang F, Pu J, Kuan SL, Chatzi C, He S, Mackie I, Brandon NJ, Marquis KL, Day M, Hurko O, McCaig CD, Riedel G, St Clair D (2008) Schizophrenia-related neural and behavioral phenotypes in transgenic mice expressing truncated Disc1. J Neurosci 28:1089310904.

Shi J, Levinson DF, Duan J, Sanders AR, Zheng Y, Pe'er I, Dudbridge F, Holmans PA, Whittemore AS, Mowry BJ, Olincy A, Amin F, Cloninger CR, Silverman JM, Buccola NG, Byerley WF, Black DW, Crowe RR, Oksenberg JR, Mirel DB, Kendler KS, Freedman R, Gejman PV (2009) Common variants on chromosome 6p22.1 are associated with schizophrenia. Nature 460:753757.

Shoji H, Toyama K, Takamiya Y, Wakana S, Gondo Y, Miyakawa T (2012) Comprehensive behavioral analysis of ENU-induced Disc1-Q31L and -L100P mutant mice. BMC Res Notes 5:108.

Singh KK, Ge X, Mao Y, Drane L, Meletis K, Samuels BA, Tsai LH (2010) Dixdc1 is a critical regulator of DISC1 and embryonic cortical development. Neuron 67:33-48. 
Singh KK, De Rienzo G, Drane L, Mao Y, Flood Z, Madison J, Ferreira M, Bergen S, King C, Sklar P, Sive H, Tsai LH (2011) Common DISC1 polymorphisms disrupt Wnt/GSK3 $\beta$ signaling and brain development. Neuron 72:545-558.

Su P, Li S, Chen S, Lipina TV, Wang M, Lai TK, Lee FH, Zhang H, Zhai D, Ferguson SS, Nobrega JN, Wong AH, Roder JC, Fletcher PJ, Liu F (2014) A dopamine D2 receptor-DISC1 protein complex may contribute to antipsychotic-like effects. Neuron 84:1302-1316.

Tsuboi D, Kuroda K, Tanaka M, Namba T, Iizuka Y, Taya S, Shinoda T, Hikita T, Muraoka S, Iizuka M, Nimura A, Mizoguchi A, Shiina N, Sokabe M, Okano H, Mikoshiba K, Kaibuchi K (2015) Disrupted-in-schizophrenia 1 regulates transport of ITPR1 mRNA for synaptic plasticity. Nature Neurosci 18:698-707.

van Os J, Bak M, Hanssen M, Bijl RV, de Graaf R, Verdoux H (2002) Cannabis use and psychosis: a longitudinal population-based study. Am J Epidemiol 156:319-327.

Wong AH, Josselyn SA (2015) Caution When Diagnosing Your Mouse with Schizophrenia: The Use and Misuse of Model Animals for Understanding Psychiatric Disorders. Biol Psychiatry (In press)

Zhou X, Chen Q, Schaukowitch K, Kelsoe JR, Geyer MA (2010) Insoluble DISC1-Boymaw fusion proteins generated by DISC1 translocation. Mol Psychiatry 15:669-672. 


\section{Behavioral manifestation}

- Emotion

- Cognition

- Perception

- Social process

4

\section{Neural circuit modulation}

- Micro-circuit regulation (Local excitatory/inhibitory circuit)

- Long-range circuitry (Cortico-striatal circuit, etc.)

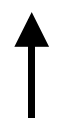

\section{Cell-to-cell communication}

- Cell type-specific regulation (Neuron vs. glia)

- Glutamatergic, GABAergic, dopaminergic etc.

\section{Molecular \& cellular mechanism}

- Neuronal development (Proliferation, migration)

- Neuronal signaling

- Synapse or spine formation \& maintenance 


\begin{tabular}{|c|c|c|c|c|}
\hline & & Haploinsufficiency & Point mutation & Dominant-negative \\
\hline \multirow{3}{*}{ Cellular } & Trafficking & $\downarrow$ (Tsuboi et al., 2015) & & \\
\hline & Oxidative stress & & & $\uparrow$ (Johnson et al., 2013) \\
\hline & $\mathrm{Ca}^{2+}$ signaling & $\uparrow$ (Park et al., 2015) & & \\
\hline \multirow{2}{*}{ Neurotransmitter } & Glutamatergic & & & $\begin{array}{l}\downarrow \text { (Booth et al., 2014; } \\
\text { Dawson et al., 2015; } \\
\text { Kim et al., 2015) }\end{array}$ \\
\hline & GABAergic & $\downarrow$ (Nakai et al., 2014) & & \\
\hline \multirow[t]{2}{*}{ Circuitry } & $\begin{array}{l}\text { Local circuitry } \\
\text { (Hippocampus) }\end{array}$ & $\downarrow$ (Kvajo et al., 2011) & & \\
\hline & $\begin{array}{l}\text { Long-range circuitry } \\
\text { (Mesocortical circuit) }\end{array}$ & & & $\downarrow$ (Niwa et al., 2013) \\
\hline \multirow{5}{*}{ Behavior } & $\begin{array}{l}\text { Sensitivity to } \\
\text { psychostimulants }\end{array}$ & & $\uparrow$ (Clapcote et al., 2007) & $\uparrow$ (Jaaro-Peled et al., 2013) \\
\hline & Prepulse inhibition & & $\downarrow$ (Clapcote et al., 2007) & $\downarrow$ (Hikida et al., 2007) \\
\hline & Working memory & $\downarrow$ (Koike et al., 2006) & $\downarrow$ (Clapcote et al., 2007) & \\
\hline & Sociability & & $\downarrow$ (Clapcote et al., 2007) & $\downarrow$ (Johnson et al., 2013) \\
\hline & Depressive like & & $\uparrow$ (Clapcote et al., 2007) & $\uparrow$ (Hikida et al., 2007) \\
\hline
\end{tabular}

$\uparrow$ Upregulated function

$\downarrow$ Downregulated function

Table 1. Cellular, neurotransmitter, circuitry, and behavioral deficits in Disc1 mouse models 


\begin{tabular}{|l|l|}
\hline \multicolumn{1}{|c|}{ Enigma } & \multicolumn{1}{|c|}{ Strategy to address enigma } \\
\hline Multiple Disc1 isoforms & Identification and functional characterization of \\
- Complex splicing events & each isoform \\
- Interchromosomal protein fusion & Detection of splicing and fusion events \\
& - Expression profiling (cell type-specific, brain region- \\
& specific and developmental expression pattern) \\
& $\begin{array}{l}\text { piochemical function (specific loss of binding partners, } \\
\text { propensity to aggregation) }\end{array}$ \\
\hline Developmental compensation & Comprehensive phenotypic characterization \\
& Comparison among mouse models \\
\hline
\end{tabular}

Table 2. Enigma of the biological roles of DISC1 